Pesq. Vet. Bras. 36(6):526-532, junho 2016

DOI: $10.1590 / \mathrm{S} 0100-736 \mathrm{X} 2016000600011$

\title{
Diferentes níveis protéicos na dieta de girinos de rã-touro (Lithobates catesbeianus) e seus efeitos sobre o tecido hepático ${ }^{1}$
}

\author{
Cleber F.M. Mansano ${ }^{2 *}$, Marcelo M. Pereira², Beatrice I. Macente ${ }^{3}$, Lilian C. \\ Makino $^{4}$, Ana P.P. Jacintho ${ }^{5}$, Laura S.O. Nakaghi ${ }^{2}$ e Marta V. De Stéfani ${ }^{2}$
}

\begin{abstract}
Mansano C.F.M., Pereira M.M., Macente B.I., Makino L.C., Jacintho A.P.P., Nakaghi L.S.O. \& De Stéfani M.V. 2016. [Different protein levels in the diet of bullfrog tadpoles (Lithobates catesbeianus) and its effects on the liver tissue.] Diferentes níveis protéicos na dieta de girinos de rã-touro (Lithobates catesbeianus) e seus efeitos sobre o tecido hepático. Pesquisa Veterinária Brasileira 36(6):526-532. Centro de Aquicultura, Universidade Estadual Paulista, Via de acesso Prof. Paulo Donato Castellane s/n, Jaboticabal, SP 14884-900, Brazil. E-mail: clebermansano@yahoo.com.br

To verify the occurrence of liver morphological changes, bullfrog tadpoles were fed three diets: an experimental diet with $32.68 \%$ crude protein and two commercial diets with $37.92 \%$ and $57.53 \%$ crude protein. Tadpoles were distributed into a completely randomized design (CRD) with three treatments and four replications. Liver samples were collected twice, on the 30th and 60th day of the experiment. Tadpole livers were fixed in Bouin's solution, then subjected to routine histotechnology procedures, and stained with hematoxylin - eosin (HE). Microscopic evaluation of liver tissue showed several morphological changes like disorganization and vacuolization of hepatocytes; periportal, multifocal and diffuse mononuclear inflammatory infiltrate, eosinophilic inflammatory infiltration, congestion, hemorrhage, hemolysis and necrosis. The liver changes found in this study suggest that diets used for bullfrog tadpoles, did not meet their dietary needs, what affected their homeostasis, thus compromising their health.
\end{abstract}

INDEX TERMS: Bullfrog, Lithobates catesbeianus, liver histology, protein, hepatocytes, liver morphology, commercial diets

RESUMO.- Para verificação da ocorrência de alterações morfológicas no fígado, foram coletados dez animais de cada dieta, no $30^{\circ}$ - dia ( $1^{\circ}$ período experimental) e no $60^{\circ}$ dia ( $2^{\circ}$ período experimental), sendo esse, o último dia do período experimental e início do clímax da metamorfose. Os girinos foram distribuídos em delineamento experimental inteiramente casualizado (DIC) com três tratamen-

\footnotetext{
${ }^{1}$ Recebido em 17 de abril de 2015.

Aceito para publicação em 22 de fevereiro de 2016.

${ }^{2}$ Centro de Aquicultura, Universidade Estadual Paulista (Unesp), Via de acesso Prof. Paulo Donato Castellane s/n, Jaboticabal, SP 14884-900, Brasil.*Autor para correspondência: clebermansano@yahoo.com.br

${ }^{3}$ Departamento de Obstetrícia e Reprodução Animal, Faculdade de Ciências Agrárias e Veterinárias (FCAV), Unesp, Via de acesso Prof. Paulo Donato Castellane s/n, Jaboticabal, SP 14884-900, Brasil.

${ }^{4}$ Departamento de Agronomia e Engenharia de Pesca, Unesp, Av. Nelson Brihi Badur 430, Vila Tupy, Registro, SP 11900-000, Brasil.

${ }^{5}$ Departamento de Patologia Veterinária, FCAV-Unesp, Via de acesso Prof. Paulo Donato Castellane s/n, Jaboticabal, SP 14884-900, Brasil.
}

tos: dieta experimental com $32,68 \%$ de proteína bruta e duas dietas comerciais com $37,92 \%$ e $57,53 \%$ de proteína bruta. Os órgãos coletados foram fixados em solução de Bouin e depois submetidos às práticas da rotina histotecnológica e coradas com hematoxilina - Eosina (HE). $\mathrm{Na}$ avaliação microscópica do fígado foram encontradas diversas alterações morfológicas como: Desorganização e vacuolização de hepatócitos, infiltrado inflamatório mononuclear periportal, multifocal e difuso, infiltrado inflamatório eosinofílico, congestão, hemorragia, hemólise e necrose. As alterações hepáticas encontradas neste estudo sugerem que as dietas utilizadas para os girinos de rã-touro, não atenderam suas necessidades dietéticas, afetando a homeostasia dos mesmos, comprometendo assim, sua sanidade.

TERMOS DE INDEXAÇ̃̃O: Rã-touro, Lithobates catesbeianus, fígado, proteína, hepatócitos, morfologia hepática, dietas comerciais. 


\section{INTRODUÇÃO}

0 adequado manejo de girinos é de fundamental importância para o bom funcionamento de um ranário, pois é desta fase que surgirão os animais aptos à etapa de recria. Nesta etapa, os animais devem estar em condições compatíveis com os índices zootécnicos, uma vez que pouco se conhece sobre as exigências nutricionais das rãs (Seixas-Filho et al. 2011b). A ocorrência de mortalidade, mutações ou desenvolvimento lento são sinais clássicos de possíveis desordens nutricionais, causados pela alimentação inadequada dos girinos (Hipólito 2003).

O desenvolvimento da ranicultura ocorrerá somente quando forem oferecidos aos girinos e rãs, alimentos com composição nutricional adequada a cada estágio de vida. Para atingir este objetivo, faz-se necessária a aquisição de maiores conhecimentos sobre os processos que envolvem a digestão dos nutrientes, o manejo alimentar e as necessidades nutricionais para cada fase de desenvolvimento, mantendo-se a homeostase dos órgãos internos (Seixas Filho et al. 2009).

0 fígado, apesar de não ser considerado um órgão digestivo (Noble, 1954), é uma glândula anexa ao tubo digestivo (Junqueira \& Carneiro 2008), atuando ativamente na digestão de gorduras através da produção de bile (Dellmann \& Brown 1982). Contudo, sua maior importância está relacionada ao armazenamento de gordura e glicogênio, eliminação de produtos nitrogenados e hemocaterese (Oliveira-Bahia et al. 2005). 0 fígado ainda possui atividade sérica de algumas enzimas como o aspartato aminotransferase (AST), alanina aminotransferase (ALT), fosfatase alcalina (FA) e gama-glutamiltransferase (GGT) (Silva et al. 2004).

0 alimento, após ser digerido no trato intestinal dos girinos, tem seus nutrientes assimilados nos hepatócitos. Assim, no caso desse órgão apresentar alguma disfunção grave, pode levar a um quadro irreversível (Hipólito et al. 2001, Guyton \& Hall 2002), com evidente diminuição da taxa de crescimento corporal do animal, podendo inclusive, levá-lo a morte.

Na literatura encontra-se grande discussão sobre qual dieta a ser ofertada aos animais, com várias opiniões que se situam em torno de 28 a $55 \%$ de proteína bruta como adequada à alimentação de girinos (Seixas Filho et al. 1998, 2010, 2011a, Mansano et al. 2012, 2014, Pinto et al. 2015). A origem da proteína dos alimentos para girinos parece não ter influência no desenvolvimento dos animais, mas sim a quantidade e qualidade deste nutriente na dieta, interferindo diretamente no crescimento dos mesmos (Stéfani et al. 1989, Stéfani \& Crivelenti 1992). Esta hipótese justifica-se até o momento por ainda não existir um perfil aminoácidico estabelecido para os girinos de rã-touro.

0 presente trabalho teve por objetivo avaliar eventuais alterações histológicas presentes no fígado de girinos de rã-touro (Lithobates catesbeianus) alimentados com uma dieta experimental e duas comerciais, com diferentes níveis proteicos, visando estabelecer uma conexão entre os fatos.

\section{MATERIAL E MÉTODOS}

O experimento foi realizado no Centro de Aquicultura da Universidade Estadual Paulista (CAUNESP), Câmpus de Jaboticabal, Laboratório de Nutrição de Organismos Aquáticos, no período com- preendido entre Novembro de 2010 a Janeiro de 2011. Todos os procedimentos descritos foram aprovados pela Comissão de Ética no Uso de Animais (CEUA) da Faculdade de Ciências de Agrárias e Veterinárias da Universidade Estadual Paulista (FCAVJ - UNESP), documento de número 025000/10, estando de acordo com os princípios éticos na experimentação animal elaborado pelo Colégio Brasileiro de Experimentação Animal (COBEA).

Foram utilizados 6.480 girinos de rã-touro no estágio 25 de Gosner (1960), alojados em 36 caixas de amianto com 100L de capacidade volumétrica, contendo $90 \mathrm{~L}$ de água, na densidade inicial de 2 girinos/L. Os girinos foram distribuídos em delineamento experimental inteiramente casualizado (DIC) com três tratamentos: dieta experimental com 32,68\% de proteína bruta (Quadro 1) e duas dietas comerciais com 37,92\% (Quadro 2) e 57,53\% de proteína bruta (Quadro 3), submetidos a quatro repetições, sendo que cada parcela experimental foi constituída por três caixas experimentais.

As análises bromatólogicas dos ingredientes utilizados na dieta experimental foram realizadas no Laboratório de Nutrição de Organismos Aquáticos do CAUNESP e no Laboratório de Nutrição Animal do Departamento de Zootecnia da FCAVJ-Unesp.

As caixas apresentavam abastecimento individual e escoamento diretamente pelo fundo. A água utilizada era proveniente de mina, livre de cloro, com renovação de $100 \%$ a cada $24 \mathrm{~h}$. Para a manutenção da qualidade da água, as caixas foram sifonadas em dias alternados para retirada de fezes e ração não consumida.

As temperaturas máxima e mínima do ambiente e da água das caixas foram medidas diariamente por meio de um termômetro digital (termômetro digital máxima e mínima - Incoterm ${ }^{\mathrm{TM}}$ ). Os valores de oxigênio dissolvido (oxímetro YSI ${ }^{\mathrm{TM}}$ linha Professional), condutividade (Condutivímetro Modelo CD-203, PHTEK $^{\mathrm{TM}}$ ) e pH (pHmetro Modelo pH-100, PHTEK $^{\mathrm{TM}}$ ) foram aferidos semanalmente.

Quadro 1. Fórmula e composição nutricional da dieta experimental na dieta de girinos de rã-touro (Lithobates catesbeianus)

\begin{tabular}{lc}
\hline Alimentos & $(\%)$ \\
\hline Farinha de peixe & 18,0 \\
Farelo de soja & 20,5 \\
Farinha de vísceras & 10,0 \\
Farelo de trigo & 17,0 \\
Farelo de milho & 17,88 \\
Amido de milho & 10,0 \\
Óleo de soja & 6,0 \\
Suplemento mineral e vitamínico ${ }^{\mathrm{a}}$ & 0,6 \\
BHT & 0,02 \\
Composição analisada $_{\text {Proteína bruta }}$ & \\
Proteína digestível & \\
Energia bruta (kcal/kg) $_{\text {Energia digestível (kcal/kg) }}^{\mathrm{b}}$ & 32,68 \\
Fibra bruta $_{\text {Matéria mineral }}$ & 26,23 \\
Extrato etéreo $_{\text {Extrativo não nitrogenado }}$ & 4434,34 \\
& 3743,07 \\
& 2,45 \\
& 7,78 \\
& 10,98 \\
& 38,13
\end{tabular}

${ }^{a}$ Umidade $(\%)=2,0$, Cinzas $(\%)=71,6442$, Colina $(\mathrm{mg} / \mathrm{kg})=30.000$, Magnésio (\%) = 0,0085, Enxofre $(\%)=1,1589$, Ferro $(\mathrm{mg} / \mathrm{kg})=25.714$, Cobre $(\mathrm{mg} / \mathrm{kg})=1.960$, Manganês $(\mathrm{mg} / \mathrm{kg})=13.345$, Zinco $(\mathrm{mg} / \mathrm{kg})=$ 30.000 , Iodo $(\mathrm{mg} / \mathrm{kg})=939$, Selênio $(\mathrm{mg} / \mathrm{kg})=30$, Vitamina $\mathrm{A}(\mathrm{UI} / \mathrm{kg})=$ 600.000 , Vitamina $\mathrm{D}_{3}(\mathrm{UI} / \mathrm{kg})=600.000$, Vitamina $\mathrm{E}(\mathrm{mg} / \mathrm{kg})=12.000$, Vitamina $K_{3}(\mathrm{mg} / \mathrm{kg})=631$, Tiamina $B_{1}(\mathrm{mg} / \mathrm{kg})=1.176$, Riboflavina $B_{2}$ $(\mathrm{mg} / \mathrm{kg})=1.536$, Piridoxina $\mathrm{B}_{6}(\mathrm{mg} / \mathrm{kg}) 1.274$, Vitamina $\mathrm{B}_{12}(\mathrm{mcg} / \mathrm{kg})$ 4.000, Niacina $(\mathrm{mg} / \mathrm{kg}) 19.800$, Acido Pantotênico $B_{3}(\mathrm{mg} / \mathrm{kg})=3.920$, Acido Fólico $(\mathrm{mg} / \mathrm{kg})=192$, Biotina $(\mathrm{mg} / \mathrm{kg})=20$, Vitamina C $(\mathrm{mg} / \mathrm{kg})$ $=40.250 .{ }^{\mathrm{b}}$ Valores calculados a partir do coeficiente de digestibilidade por Secco et al. (2005). 
Quadro 2. Nível de garantia do fabricante (NGF) e composição centesimal analisada (CCA) da Ração Comercial 1

\begin{tabular}{lcc}
\hline & NGF & CCA \\
\hline Proteína bruta (\%) & 35,0 (min) & 37,92 \\
Extrato etéreo (\%) & - & 7,53 \\
Energia bruta (kcal/kg) & - & 4156,34 \\
Fibra bruta (\%) & - & 3,35 \\
Matéria Mineral (\%) & - & 10,95
\end{tabular}

Composição básica da ração: Milho integral moído, farelo de soja, farelo de glúten de milho $=60$, farinha de carne e ossos, farinha de penas hidrolisadas, farinha de sangue, gordura vegetal estabilizada, cloreto de sódio (sal comum), cloreto de colina, calcário calcítico. Eventuais substitutivos: sorgo integral moído, quirera de arroz, farelo de milho, farelo de glúten de milho, farelo de trigo, farelo de arroz, levedura seca de cana de açúcar. Suplemento mineral e vitamínico: Vitamina A ( $\mathrm{min})=35.000$ U.I., Vitamina $\mathrm{D}_{3}(\mathrm{~min})=2.000$ U.I., Vitamina $\mathrm{E}(\mathrm{min})=120$ U.I., Vitamina $\mathrm{K}_{3}(\mathrm{~min})$ $=800 \mathrm{mg}$, Ácido fólico $(\mathrm{min})=10 \mathrm{mg}$, Biotina $(\mathrm{min})=10 \mathrm{mg}$, Tiamina $\left(\mathrm{B}_{1}\right)$ $=(\mathrm{min})=25 \mathrm{mg}$, Riboflavina $\left(\mathrm{B}_{2}\right)(\mathrm{min})=35 \mathrm{mg}$, Piridoxina $\left(\mathrm{B}_{6}\right)(\mathrm{min})=$ $40 \mathrm{mg}$, Vitamina $B_{12}(\mathrm{~min})=100 \mathrm{mcg}$, Niacina $(\mathrm{min})=350 \mathrm{mg}$, Acido Pantotênico $(\mathrm{min})=150 \mathrm{mg}$, Colina $(\mathrm{min})=2.500 \mathrm{mg}$, Cobre $(\mathrm{min})=25 \mathrm{mg}$, Ferro $(\mathrm{min})=150 \mathrm{mg}$, Manganês $(\mathrm{min})=75 \mathrm{mg}$, Selênio $(\mathrm{min})=1 \mathrm{mg}$, Zinco $(\mathrm{min})=140 \mathrm{mg}$, Mananoligossacarídeo $(\mathrm{min})=60 \mathrm{mg}$.

Quadro 3. Nível de garantia do fabricante (NGF) e composição centesimal analisada (CCA) da Ração Comercial 2

\begin{tabular}{lcc}
\hline & NGF & CCA \\
\hline Umidade (\%) & 10,0 (max) & - \\
Proteína bruta (\%) & $55,0(\min )$ & 57,53 \\
Extrato etéreo (\%) & $7,0(\min )$ & 8,43 \\
Energia bruta (kcal/kg) & - & 5003,08 \\
Fibra bruta (\%) & $2,8(\max )$ & - \\
Minerais (\%) & $17,0(\max )$ & 10,92 \\
Ca (\%) & $4,2(\max )$ & - \\
Fósforo (\%) & $1,5(\min )$ & -
\end{tabular}

Composição básica da ração: Milho integral moído, farelo de soja, farelo de glúten de milho $=60$, farinha de carne e ossos, farinha de penas hidrolisadas, farinha de sangue, gordura vegetal estabilizada, cloreto de sódio (sal comum), cloreto de colina, calcário calcítico. Eventuais substitutivos: sorgo integral moído, quirera de arroz, farelo de milho, farelo de glúten de milho, farelo de trigo, farelo de arroz, levedura seca de cana de açúcar. Suplemento mineral e vitamínico: Vitamina A (min) = 35.000 UI, Vitamina $\mathrm{D}_{3}(\mathrm{~min})=2.000 \mathrm{UI}$, Vitamina $\mathrm{E}(\mathrm{min})=120$ UI, Vitamina $\mathrm{K}_{3}(\mathrm{~min})=800=\mathrm{mg}$, Ácido fólico $(\mathrm{min})=10=\mathrm{mg}$, Biotina $(\mathrm{min})=10 \mathrm{mg}$, Tiamina $\left(\mathrm{B}_{1}\right)=(\mathrm{min})=25 \mathrm{mg}$, Riboflavina $\left(\mathrm{B}_{2}\right)(\mathrm{min})=35 \mathrm{mg}$, Piridoxina $\left(B_{6}\right)(\mathrm{min})=40 \mathrm{mg}$, Vitamina $B_{12}(\mathrm{~min})=100 \mathrm{mcg}$, Niacina $(\mathrm{min})=350 \mathrm{mg}$, Acido Pantotênico $(\mathrm{min})=150 \mathrm{mg}$, Colina $(\mathrm{min})=2.500 \mathrm{mg}$, Cobre $(\mathrm{min})$ $=25 \mathrm{mg}$, Ferro $(\mathrm{min})=150 \mathrm{mg}$, Manganês $(\mathrm{min})=75 \mathrm{mg}$, Selênio $(\mathrm{min})=1$ $\mathrm{mg}$, Zinco $(\mathrm{min})=140 \mathrm{mg}$, Mananoligossacarídeo $(\mathrm{min})=60 \mathrm{mg}$.

As coletas foram realizadas no $30^{\circ}$ dia (1ำ período experimental) e no $60^{\circ}$ dia ( $2^{\circ}$ período experimental), sendo esse, o último dia do período experimental e início do clímax da metamorfose. Em cada coleta, dez animais de cada dieta, foram acondicionados em recipientes com água a $-4^{\circ} \mathrm{C}$, intuindo a redução do metabolismo e, em seguida, anestesiados em solução de óleo de cravo (150mg/L). Seguiu-se com a insensibilização por contenção fisiológica, por meio da secção transversal da medula espinhal e efetuada a necropsia para verificação da ocorrência de alterações na morfologia dos órgãos internos com destaque para o fígado.

Os órgãos foram fixados em solução de Bouin por $24 \mathrm{~h}$, enxaguados em solução alcoólica a 70\% para completa eliminação do fixador e depois submetidos às práticas da rotina histotecnológica, que envolveram as etapas de desidratação gradual das amostras em solução alcoólica etílica com concentrações crescentes, de diafanização dos tecidos em xileno (xilol) e inclusão dos fragmentos em His- tosec $^{\mathrm{TM}}$. Após a inclusão, as amostras foram cortadas ao micrótomo na espessura de $4,0 \mu$, montadas em lâminas, coradas com hematoxilina e Eosina (HE) e, finalmente visualizadas em microscópio de luz.

\section{RESULTADOS}

As temperaturas mínima e máxima da água das caixas durante o período experimental variaram de $24,2 \pm 1,4^{\circ} \mathrm{C}$ a $26,0 \pm 1,2^{\circ} \mathrm{C}$, respectivamente. Os valores médios de oxigênio dissolvido, condutividade elétrica e pH da água das caixas durante o período experimental foram $3,07 \pm 0,92 \mathrm{mg} / \mathrm{l}$, $38,0 \pm 0,26 \mu \mathrm{S} . \mathrm{cm}^{-1}$ e $6,17 \pm 0,34$, respectivamente.

0 fígado dos animais que receberam as dietas comerciais durante todo o período experimental, que compreendeu 60 dias, apresentaram-se macroscopicamente aumentados de tamanho, hipocorados, flácidos e friáveis, sugerindo a ocorrência de alterações na estrutura microscópica do tecido hepático. No entanto, os animais alimentados com a dieta experimental apresentaram os órgãos com arquitetura e coloração preservados macroscopicamente.

No $30^{\circ}$ dia do período experimental foi observado na análise histológica hepática dos animais que receberam a dieta formulada com $32,68 \%$ de proteína bruta, discreta a moderada desorganização dos hepatócitos, que se apresentaram hipertrofiados, moderada vacuolização citoplasmática e severa quantidade de grânulos. Os manguitos perivasculares observados mostraram-se compostos por células mononucleares, distribuídas periportal e também difusamente pelo parênquima, indicando um processo inflamatório crônico no tecido hepático. (Fig.1a) Quatro animais apresentaram infiltrado inflamatório eosinofílico. Houve congestão de moderada a severa em seis animais; hemorragia em dois animais; hemólise em sete e necrose em apenas um animal.

Ao final do experimento (60 dia), o fígado dos animais alimentados com a dieta experimental contendo 32,68\% de proteína bruta apresentaram severa desorganização da arquitetura histológica do órgão. Observaram-se variados graus de congestão nos sinusóides, áreas com proliferação de tecido conjuntivo denso, sugerindo um processo fibrótico do parênquima. Os hepatócitos mostraram intensa vacuolização do citoplasma, perdendo suas características morfológicas normais. (Fig.2a). Houve discreta a moderada vacuolização e moderada a severa quantidade de grânulos. $\mathrm{O}$ infiltrado inflamatório mononuclear foi moderado a severo, com distribuição periportal e difusa na maioria dos animais. Apenas seis animais apresentaram moderado a severo infiltrado inflamatório mononuclear multifocal. Houve moderada a severa congestão (Fig.2a).

0 tecido hepático dos girinos alimentados com a dieta comercial de $37,92 \%$ de proteína bruta, no $30^{\circ}$ dia do experimento, apresentou graus variados na desorganização na sua arquitetura morfológica, de moderado a severo. A vacuolização citoplasmática dos hepatócitos foi intensa, sugerindo um possível processo de esteatose, devido ao formato perfeitamente arredondado das vesículas. Notou-se também a presença de um discreto infiltrado inflamatório mononuclear, com distribuição periportal e também difusamente pelo parênquima. Houve também uma discreta congestão dos sinusóides (Fig.1b). 

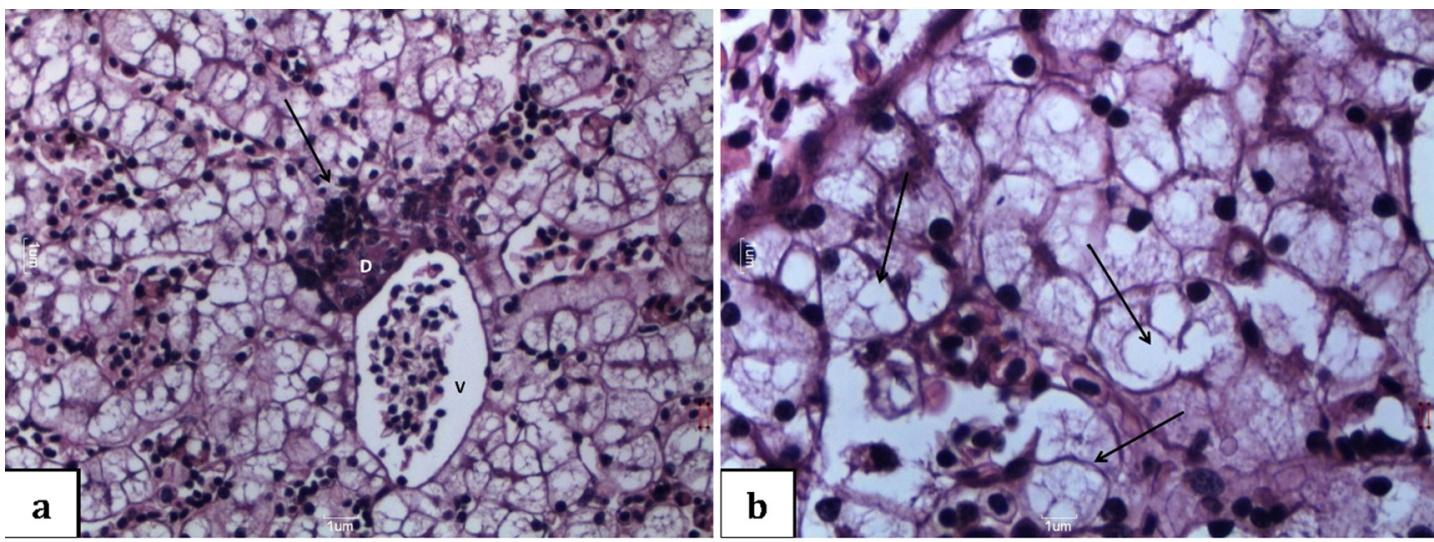

Fig.1. Fígado de girinos de rã-touro, Lithobates catesbeianus, no $30^{\circ}$ dia do período experimental. (a) Girinos alimentados com dieta experimental $(32,68 \%$ de proteína bruta), severa degeneração vacuolar, hepatócitos desorganizados e congestão. Infiltrado inflamatório mononuclear periportal (Seta). Veia central do lóbulo (V). Ducto biliar (D). HE, obj. 20x. (b) Girinos alimentados com dieta experimental $(37,92 \%$ de proteína bruta), hepatócitos hipertrofiados, marginalização do núcleo celular e citoplasma severamente vacuolizado, sugerindo grave quadro de esteatose (setas). HE, obj.40x. (c) Girinos alimentados com dieta experimental

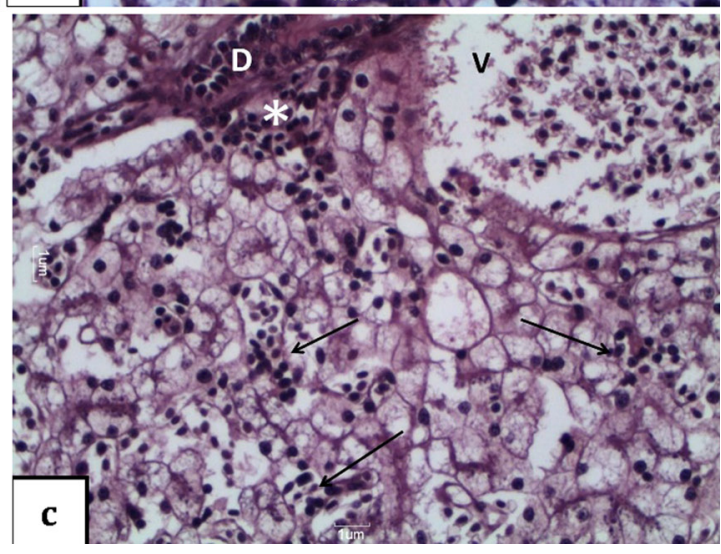
(57,53\% de proteína bruta), degeneração dos hepatócitos e perda da arquitetura estrutural do órgão; presença de infiltrado inflamatório mononuclear distribuído difusamente por todo o parênquima hepático (setas). Espaço periportal (*). Veia central do lóbulo (V). Ducto biliar (D). HE, obj.20x.

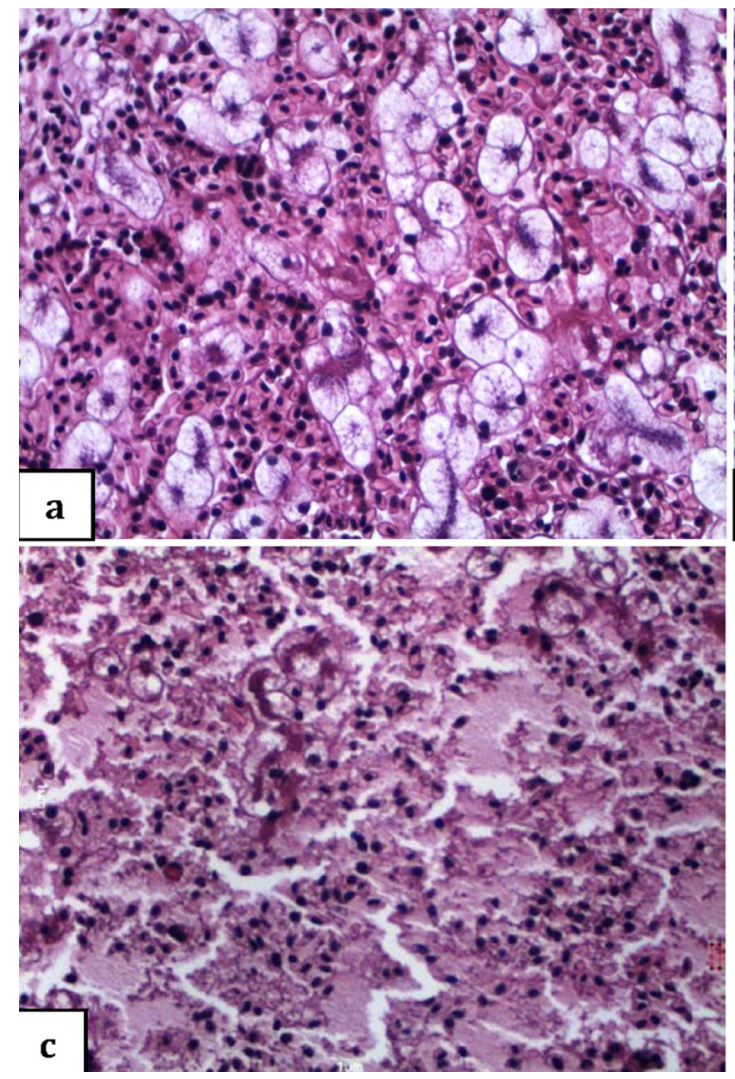

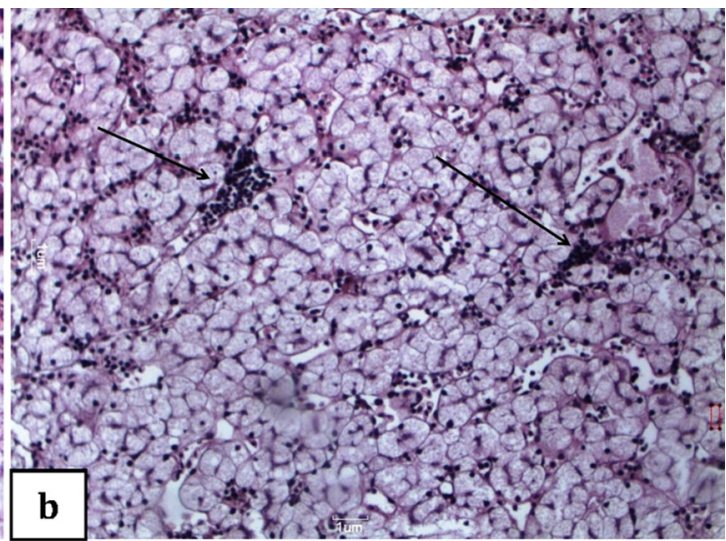

Fig.2. Fígado de girinos de rã-touro, Lithobates catesbeianus no $60^{\circ}$ dia do período experimental. (a) Girinos alimentados com dieta experimental (32,68\% de proteína bruta), com severa congestão e dilatação dos espaços dos sinusoidais, levando a desorganização de hepatócitos (setas). HE, obj.20x. (b) Girinos alimentados com dieta comercial $(37,92 \%$ de proteína bruta), com infiltrado inflamatório mononuclear multifocal (setas), demonstrando um quadro de hepatite crônica. HE, obj.20x. (c) Girinos alimentados com dieta comercial $(57,53 \%$ de proteína bruta), com necrose severa e difusa. HE, obj.20x. 
Após nova avaliação do grupo de girinos alimentados com $37,92 \%$ de proteína bruta aos 60 dias de experimento, verificou-se moderada desorganização de hepatócitos. Houve intensa vacuolização, presença de infiltrados inflamatórios de células mononucleares, com distribuição difusa e periportal (Fig.2b). Nove animais apresentaram infiltrado inflamatório eosinofílico subcapsular. Os animais apresentaram moderada a severa congestão, sendo que em cinco casos houve hemorragia e hemólise.

No terceiro grupo de girinos alimentados com a dieta comercial com $55,0 \%$ de proteína bruta, constatou-se aos 30 dias de experimento, moderada desorganização da arquitetura histológica do parênquima hepático, com acentuada vacuolização citoplasmática nos hepatócitos, sugerindo a presença de esteatose e degeneração hidrópica, com distribuição difusa. 0 infiltrado inflamatório mononuclear foi predominante e esteve distribuído difusamente por todo o parênquima hepático (Fig.1c). Observou-se apenas um caso em que a distribuição foi multifocal. Os fígados apresentaram moderada a severa congestão e em três casos constatou-se hemorragia subcapsular. Apenas um animal apresentou hemólise e outro, necrose.

$\mathrm{Na}$ análise hepática final dos animais alimentados com $55,0 \%$ de proteína bruta aos 60 dias de experimento, verificou-se desorganização de hepatócitos de discreta a moderada. Observou-se discreta a moderada vacuolização e presença de grânulos. Houve discreto a moderado infiltrado inflamatório mononuclear periportal e moderado a severo infiltrado inflamatório mononuclear difuso. Notou-se em um animal, infiltrado inflamatório eosinofílico subcapsular. Foi constatada congestão moderada a severa, porém apenas um animal apresentou hemorragia e necrose severa e difusa. (Fig.2c)

\section{DISCUSSÃO}

A temperatura da água interfere diretamente no metabolismo dos anfíbios, devido ao fato de serem ectotérmicos, aumentando a velocidade de crescimento e ganhos de massa corpórea quando em condições térmicas favoráveis (Hoffmann et al. 1989).

Os valores de temperatura de máxima e mínima da água estão dentro da faixa considerada ótima $\left(24,5-29,1^{\circ} \mathrm{C}\right)$ para cultivo de girinos (Lima et al. 2003, Bambozzi et al. 2004, Hayashi et al. 2004, Seixas Filho et al. 2008). Os teores médios de oxigênio dissolvido na água estão dentro do limite aceitável para o cultivo de girinos (Hailey et al. 2006).

A condutividade elétrica da água das caixas experimentais encontrou-se dentro dos parâmetros indicados por Sipaúba-Tavares (1994) entre 23,0 e 71,0 $\mu$ S.cm para o cultivo de organismos aquáticos em viveiros escavados. Os valores médios do potencial hidrogeniônico $(\mathrm{pH})$ da água das caixas, também estão dentro da faixa compreendida entre 6,0 e 7,0, considerada ideal para o cultivo de girinos de rã-touro (Alves 1995) e próximos ao valor de 6,5 encontrados por Albinati et al. (2001). De maneira geral, os parâmetros hídricos apresentaram-se relativamente constantes em todas as caixas.

Atualmente, a maior parte das dietas utilizadas para rã-touro é advinda da piscicultura, não havendo uma die- ta específica para rãs nas diferentes etapas de criação. A ausência deste produto no mercado ranícola nacional acarreta vários problemas, podendo interferir diretamente no processo nutricional das rãs. Como essas formulações tendem a suprir as exigências nutricionais dos peixes, acaba-se fornecendo um alimento não balanceado aos girinos, e como consequência, há o surgimento de deficiência protéica e lesões hepáticas (Hipólito 2003).

0 fígado é de grande importância para os girinos, pois além de atuar como parte dos processos digestivos, também possui função imunológica. Logo, seus distúrbios apresentam consequências de longo alcance sobre a homeostasia corpórea (Seixas Filho et al. 2008). Quando há uma inadequada alimentação protéico-calórica prolongada, desenvolvem-se várias síndromes generalisadas, inclusive afetando a resitência imunológica destes animais (Seixas Filho et al. 2009). 0 fígado ainda pode apresentar desordens orgânicas devido a intoxicações, infecções ou parasitismo, por meio de alterações na sua estrutura celular, bioquímica e morfológica (Freitas et al. 2014).

Dentre os distúrbios hepáticos encontrados no presente trabalho, destaca-se a degeneração gordurosa que é o acúmulo anormal de gorduras no citoplasma de células que normalmente não as armazenam. 0 fígado é o local mais comum desta lesão, identificada microscopicamente pela presença de vacúolos no tecido hepático, porém ocorre também no epitélio dos túbulos renais e nas fibras miocárdicas (Montenegro \& Franco 1999).

0 acúmulo de gorduras nos hepatócitos ocorre quando há uma discrepância entre o volume de gorduras que chegam ou que são sintetizadas no fígado, e o volume de gorduras que são utilizadas ou que são secretadas como lipoproteínas pelo fígado (Woolf 2000).

Neste trabalho, a degeneração gordurosa pode ter sido desencadeada por danos específicos ou inespecíficos aos hepatócitos, ocasionados diretamente pelas deficiências nutricionais que reduzem a síntese de proteínas. Essa alteração leva à diminuição da síntese de lipoproteínas, resultando em acúmulo de gorduras hepáticas. Ou seja, o animal necessita de um balanço ideal em aminoácidos e não em proteína. Quando não há este balanço, ocorre um aumento da mobilização de gorduras dos depósitos para aproveitamento energético, causando o acúmulo no hepatócito, pela carência de alguns aminoácidos (Robbins et al. 1996, Tattersall \& Ultsch 2008).

As alterações morfológicas encontradas no tecido hepático são decorrentes de alterações funcionais, denominadas de degenerações. Essas degenerações são alterações regressivas das células que se manifestam por modificações citoplasmáticas e nucleares e, por diminuição da função celular (Kumar et al. 2010). Geralmente, as alterações degenerativas são consideradas reversíveis, uma vez que as funções celulares retornam ao normal quando eliminado o agente causal, como a correção de uma alimentação inadequada.

No entanto, quando a capacidade homeostática da célula é superada pela intensidade ou duração da agressão, ocorre uma lesão irreversível. Pode-se afirmar que existe um limite entre o "ponto de retorno e não retorno" da funcionalidade de uma determinada célula. Quando este limite 
é ultrapassado segue-se um período de desorganização estrutural progressiva, que culmina com a morte celular ou necrose (Fabris 1992).

Nesse estudo foi observado um grande número de animais com a presença de necrose hepática, apresentando um conjunto de alterações morfológicas que ocorrem após a morte celular. A diminuição das atividades vitais das células determina uma série de alterações morfológicas que podem ser consideradas como sinal da ocorrência da morte celular, ocasionando a diminuição da homeostase corporal destes animais, interferindo diretamente nos parâmetros de desenvolvimento dos mesmos.

0 tecido necrosado, de modo geral, apresenta-se como um elemento estranho ao organismo, que procura eliminá-lo. 0 modo de eliminação depende da extensão da massa necrosada, do local onde se localiza e da causa da necrose. Como resultado, pode ocorrer: absorção, drenagem, cicatrização e calcificação, encistamento e a gangrena (Kumar et al. 2008). Isso explica o fato de terem sidos encontrados alguns infiltrados mononucleares difusos e localizados em pontos do tecido hepático, demonstrando a reação do organismo frente a essa alteração homeostática.

A falta de uma dieta para girinos interfere diretamente no processo nutricional, porque durante esta fase, são animais onívoros (Oliveira-Bahia 2007) e muitas vezes acabam recebendo uma dieta para peixes carnívoros. Muitas das alterações observadas nesse estudo também foram encontradas por Hipolito et al. (2004), Seixas filho et al. (2013) e Freitas et al. (2014) avaliando o fígado de rãs-touro adultas, sugerindo que a utilização de uma dieta de má qualidade leva a uma disfunção do tecido hepático.

\section{CONCLUSÃO}

As alterações hepáticas encontradas neste estudo sugerem que as dietas utilizadas para os girinos de rã-touro, não atenderam suas necessidades dietéticas, afetando a homeostasia dos mesmos, comprometendo assim, sua sanidade.

Agradecimentos.- À Fundação de Amparo à Pesquisa do Estado de São Paulo (FAPESP), pela concessão de bolsa de mestrado (processo $\mathrm{n}^{-}$ 2010/14721-3) e ao auxílio pesquisa (processo no 2011/50865-2).

\section{REFERÊNCIAS}

Albinati R.C.B., Lima S.L. \& Donzele J.L. 2001. Níveis de energia digestível na ração de girinos de rã-touro. Revta Bras. Saúde Prod. Anim. 2:48-52.

Alves A.R. 1995. Estudo comparativo da criação de girinos de rã-touro (Rana catesbeiana Shaw, 1802) em dois tipos de tanque. Dissertação de Mestrado em Zootecnia, Universidade Federal de Viçosa, Viçosa, MG. 53p.

Bambozzi C.A., Teixeira Seixas J., Thomaz L.A. \& Oshiro M.Y. 2004. Efeito do fotoperíodo sobre o desenvolvimento de girinos de rã-touro (Rana catesbeiana Shaw, 1802). Revta Bras. Zootec. 33:1-17.

Dellmann H.D. \& Brown E.M. 1982. Histologia Veterinária. Guanabara Koogan, Rio de Janeiro. 397p.

Fabris V.E. 1992. Lesões celulares reversíveis e irreversíveis, p.35-71. In: Montenegro M.R. \& Franco M. (Eds), Patologia: processos gerais. 3aㅡ ed. Atheneu, São Paulo.

Freitas J.J.G., Bach E.E., Bondon I.C.A.C., Martins A.M.C.R.P.F., Hipolito M. \& Ferreira. 2014. Resposta hepática à suplementação alimentar em rãs-touro sob condição de estresse. Bolm. Inst. Pesca, São Paulo, 40(2):261269.
Gosner K.L. 1960. A simplified table for staging anuran embryos and larvae with notes on identification. Herpetologica 16:183-190.

Guyton A.C. \& Hall J.E. 2002. Tratado de Fisiologia Médica. 4르 ed. Guanabara-Koogan, Rio de Janeiro. 972p.

Hailey A., Sookoo N., Mohammed A. \& Khan A. 2006. Factors affecting tadpole growth: development of a rearing system for the Neotropical leptodactylid Physalaemus pustulosus for ecotoxicological studies. Appl. Herpetol. 3:111-128.

Hayashi C., Soares C.M., Galdioli E.M., Furuya V.R.B. \& Boscolo W.R. 2004. Desenvolvimento de girinos de rã-touro (Rana catesbeiana Shaw, 1802) cultivados em diferentes densidades de estocagem em tanque-rede. Revta Bras. Zootec. 33:14-20.

Hipólito M. 2003. Deficiência protéica e demais patologias associadas ao fígado de rãs-touro (Rana catesbeiana Shaw, 1802). Bolm Inst. Pesca, São Paulo, 34:29-33.

Hipólito M., Leme M.C.M. \& Bach E.E. 2001. Lesões anátomo-histopatológicas em rãs-touro (Rana catesbeiana Shaw, 1802) associadas à deterioração da ração. Arqs Inst. Biológico, São Paulo, 68:111-114.

Hipólito M., Martins A.M.C.R.P.F. \& Bach E.E. 2004. Aspectos bioquímicos em fígados de rã-touro (Rana catesbeiana Shaw, 1802) sadias e doentes. Arqs Inst. Biológico, São Paulo, 71:147-153.

Hoffmann D.F., Leboute E.M. \& Souza S.M.G. 1989. Efeito da temperatura e desenvolvimento de girinos de rã-touro (Rana catesbeiana Shaw, 1802). Revta Socied. Bras. Zootec. 18:557-566.

Junqueira L.C. \& Carneiro J. 2008. Histologia Básica: texto e atlas. 11ª̣ ed. Guanabara Koogan, Rio de Janeiro. 542p.

Kumar V., Abbas A.K., Fausto N. \& Aster J.C. 2010. Robbins e Cotran Patologia: bases patológicas das doenças. 8ª ed. Elsevier, Rio de Janeiro. 1480p.

Kumar V., Abbas A.K., Fausto N. \& Mitchell R.N. 2008. Robbins Patologia Básica. 8a ed. Elsevier, Rio de Janeiro. 1048p.

Lima S.L., Casali A.P. \& Agostinho C.A. 2003. Desempenho zootécnico e tabela de alimentação de girinos de rã-touro (Rana catesbeiana) criados no sistema anfigranja. Revta Bras. Zootec. 32:512-518.

Mansano C.F.M., Stéfani M.V., Pereira M.M. \& Macente B.I. 2012. Non-linear growth models for bullfrog tadpoles. Ciênc. Agrotec. 36:454-462.

Mansano C.F.M., Stéfani M.V., Pereira M.M., Nascimento T.S.R. \& Macente B.I. 2014. Morphometric growth characteristics and body composition of bullfrog tadpoles in captivity. Semina: Ciênc. Agrárias 35:1425-1438.

Montenegro M.R. \& Franco M. 1999. Patologia: processos gerais. $4^{\text {a }}$ ed. Atheneu, São Paulo. 320p.

Noble G.K. 1954. The digestive system, p.201-211. In: Noble G.K. (Ed.), Biology of the Amphibian. Dover Publication Inc, New York. 577p.

Oliveira-Bahia V.R.L. 2007. Morfologia e enzimologia do sistema digestório dos girinos da rã-touro (Rana catesbeiana) durante o desenvolvimento e metamorfose. Tese de Doutorado em Aquicultura, Centro de Aquicultura, Universidade Estadual Paulista, Jaboticabal, SP. 148p.

Oliveira-Bahia V.R.L., Buttler L., De Stéfani M.V., Varella M.H.C., Pizauro J.M \& Nakaghi L.S.O. 2005. Development of the gastroenteric region in Rana catesbeiana tadpoles during the metamorphosis process. Braz. J. Morphol. Sci. 22:158-159.

Pinto D.F.H., Mansano C.F.M., De Stéfani M.V. \& Pereira M.M. 2015. Optimal digestible protein level for bullfrog tadpoles. Aquaculture 440:12-16.

Robbins S., Cotran R. \& Kumar V. 1996. Fundamentos de Robbins: patologia estrutural e funcional. 5a ed. Guanabara Koogan, Rio de Janeiro. 605p.

Secco E.M., Stéfani M.V. \& Vidotti R.M. 2005. Apparent digestibility of different ingredients in diets for bullfrog Rana catesbiana tadpoles. J. World Aquacult. Soc. 36:135-140.

Seixas Filho J.T., Hipolito M., Carvalho V.F., Martins A.M.C.R.P.F., Silva L.N. \& Castagna A.A. 2008. Alterações histopatológicas em girinos de rã-touro alimentados com rações comerciais de diferentes níveis protéicos. Revta Bras. Zootec. 37:2085-2089.

Seixas Filho J.T., Hipolito M., Martins A.M.R.P.F., Rodrigues E., Castagna A.A. \& Mello S.C.R.P. 2009. Histopathological alterations in bullfrog juveniles fed commercial rations of different crude protein levels. Revta Bras. Zootec. 38:2306-2310. 
Seixas Filho J.T., Hipólito M., Pereira M.M., Martins A.C.R.P.P., Rodrigues E. \& Mello S.C.R.P. 2013. Liver histopathological changes in breeding bullfrogs. Acta Scient. Anim. Sci. 35:461-465.

Seixas Filho J.T., Navarro R.D., Silva L.N. \& Souza L.N. 2011a. Alimentação de girinos de rã-touro com diferentes níveis de proteína bruta. Ciênc. Anim. Bras. 12:250-256.

Seixas Filho J.T., Navarro R.D., Silva L.N., Garcia S.L.R. \& Hipólito M. 2010. Desempenho de girinos de rã-touro alimentados com ração comercial contendo diferentes concentrações de proteína bruta. Revta Bras. Ciênc. Agrárias 5:428-433.

Seixas Filho J.T., Oliveira M.G.A., Navarro R.D., Garcia S.L.R., Moura G.S. \& Ribeiro Filho 0.P. 2011b. Atividades enzimáticas de girinos de rã-touro submetidos a rações com níveis de proteína. Arch. Zootec. 60:11611170.

Seixas-Filho J.T., Mello S.C.R.P., Silva J.M.F., Tomas J.E. \& Melo C.M.S. 1998. Efeito dos níveis de energia e proteína bruta no desempenho de girinos (Rana catesbeiana Shaw, 1802). Revta Bras. Zootec. 27:664-669.
Silva L.P., Miyasaka C.K., Martins E.F., Leite Jr S.A., Lacava Z.G.M., Curi R. \& Azevedo R.B. 2004. Effect of bullfrog (Rana catesbeiana) oil administered by gavage on the fatty acid composition and oxidative stress for mouse rdliver. Braz. J. Med. Biol. Res. 37:1491-1496.

Sipaúba-Tavares L.H. 1994. Limnologia Aplicada à Aquicultura. Funep, Jaboticabal. 70p.

Stéfani M.V. \& Crivelenti G. 1992. Níveis protéicos e proporções de protéinas de origem animal em dietas artificiais para girinos de rã-touro (Rana catesbeiana Shaw, 1802). Anais 7o Simpósio Brasileiro de Aquicultura, Peruíbe, SP, p.183-190. (Resumo)

Sféfani M.V., Carneiro D.J. \& Dias T.C.R. 1989. Exigências protéicas em dietas para girinos de rã-touro, Rana catesbeiana (Shaw, 1802). Ciênc. Zootéc. 4:8-11.

Tattersall G.J. \& Ultsch G.R. 2008. Physiological ecology of aquatic overwintering in ranid frogs. Biol. Rev. 83:119-140.

Woolf N. 2000. Cell, Tissue and Disease: the basis of pathology. 3rd ed. W.B. Saunders, Edinburgh. 